\title{
Effect of visfatin on the function of endothelial progenitor cells in high-fat-fed obese rats and investigation of its mechanism of action
}

\author{
YANG SUN $^{1-3}$, SHUCHUN CHEN $^{1,2}$, GUANGYAO SONG $^{1,2}$, LUPING REN $^{1,2}$, LIMIN WEI $^{1,2}$, \\ NA LIU ${ }^{1,2}$, DONEMEI ZHANG ${ }^{1,2}$ and XIUQIN LV ${ }^{1,2}$ \\ ${ }^{1}$ Department of Endocrinology, Hebei General Hospital, Shijiazhuang, Hebei; ${ }^{2}$ Hebei Research Institute \\ for Endocrine and Metabolic Diseases, Shijiazhuang, Hebei; ${ }^{3}$ Department of Internal Medicine, \\ Taishan Sanatorium of Shandong, Taian, Shandong, P.R. China
}

Received February 12, 2012; Accepted April 9, 2012

DOI: $10.3892 /$ ijmm.2012.1032

\begin{abstract}
The aim of this study was to study the quantity change of endothelial progenitor cells (EPCs) in obese rats fed a high-fat-diet and to investigate the correlation of EPC numbers with visfatin. The impact of visfatin on the quantity and function of EPCs were further investigated by cell culture methods. Male Wistar rats were fed on either a standard diet (NC group) or a high-fat diet (HF group) for 16 weeks. Serum visfatin, Lee's index and the protein expression of visfatin in viseral adipose tissue (VAT) were determined. Bone marrow EPCs in 2 groups of rats were isolated, cultured and counted. EPCs primarily cultured from control male Wistar rats were treated with different concentrations of visfatin. The quantity, migration and adhesion capacity of EPCs were evaluated after visfatin treatment. Protein expression of nuclear factor- $\kappa \mathrm{B}$ $(\mathrm{NF}-\kappa \mathrm{B})$ in the nuclei of EPCs was detected. After 16-week feeding, body weight, serum visfatin, Lee's index and visfatin contents in viseral fat were significantly increased in the HF group compared with $\mathrm{NC}$ group $(\mathrm{P}<0.01$ or $\mathrm{P}<0.05)$. The quantity of EPCs primarily cultured from rats in HF group was lower than that in NC group. The quantity of EPCs was
\end{abstract}

Correspondence to: Dr Shuchun Chen, Department of Endocrinology, Hebei General Hospital, Shijiazhuang, Hebei 050051, P.R. China

E-mail: guang6701@sina.com

Abbreviations: EPCs, endothelial progenitor cells; VAT, visceral adipose tissue; NF- $\kappa \mathrm{B}$, nuclear factor- $\kappa \mathrm{B}$; MNCs, marrow mononuclear cells; EGM-2MV, endothelial growth media-2MV; $\mathrm{KDR}$, kinase insert domain receptor; Flk-1, fetal liver kinase-1; DAB, diaminobenzidine; DiI-acLDL, DiI-labeled acetylated LDL; FITCLectin-UEA-1, fluorescein isothiocyanate-conjugated lectin from Ulex europaeus agglutinin; BW, body weight; FBG, fasting blood glucose; FINS, fasting insulin in serum; TG, triglyceride; TC, total cholesterol; ICAM-1, intercellular adhesion molecule 1; VCAM-1, vascular cell adhesion molecule 1 ; TNF- $\alpha$, tumor necrosis factor- $\alpha$; MMP-9, matrix metalloproteinase-9; IL-8, interleukin-8; IR, insulin receptor; Ras-MAPK, Ras-mitogen-activated protein kinases

Key words: visfatin, endothelial progenitor cells, obesity negatively correlated with serum visfatin levels, visceral fat, fasting blood glucose, HOMA-IR, total cholesterol, triglyceride and body weight $(\mathrm{P}<0.01)$. In cultured EPCs, visfatin significantly increased the protein expression of $N F-\kappa B$ in EPC nuclei $(\mathrm{P}<0.01)$ in a dose-dependent manner. The migration and adhesion capacity were impaired by visfatin treatment $(\mathrm{P}<0.01)$. In conclusion, bone marrow-derived EPCs decrease in number and have impaired migration and adhesion function in high-fat-fed obese rats, along with increased serum visfatin and protein contents in VAT. Visfatin may have an impact on the quantity and function of EPCs through the NF- $\kappa$ B pathway.

\section{Introduction}

With the change of life style and diet structure, obesity has become increasingly prevalent all over the world. The incidence of obesity is attributable to many interrelated factors, of which high-calorie intake, high-fat diet and lack of physical activity are important risk factors. Excess energy is stored as fat and leads to obesity. Moreover, obesity is closely associated with the development of many diseases, including hypertension, type 2 diabetes, metabolic syndrome, dyslipidemia. The excessive accumulation of visceral adipose tissue, especially the accumulation of abdominal adipose tissue is an important risk factor of cardiovascular disease.

Endothelial progenitor cells (EPCs) originate from bone marrow and are progenitor cells which have the capacity to migrate to the peripheral circulation and to differentiate into mature endothelial cells. Under the circumstances of vessel impairment and tissue ischemia, the EPCs in the bone marrow can be mobilized into the blood circulation and settle in impaired and ischemic locations. EPCs are then differentiated into mature endothelial cells and participate in angiogenesis and re-endothelialization. Therefore, EPCs play an important role in maintaining the integrity of endothelial structures and the function of vascular endothelium. EPCs are influenced by many factors, such as physical activity and smoking $(1,2)$. Many diseases can cause the decrease in the quantity of EPCs. EPCs in diabetic patients decrease significantly in quantity with an impaired restoration capacity of vessels (3-5). Hyperglycemia, hyperinsulinemia and hyperlipidemia can all lead to the impairment of EPCs. 
Overweight and obesity are closely related to the incidence and mortality of cardiovascular diseases. According to the studies, dysfunction of vascular endothelium exists in overweight and obese populations. Because endothelial damage and dysfunction are considered to be a major underlying mechanism for cardiovascular disease, the prompt endothelial repair/regeneration is very meaningful in maintaining a normal endothelium function and preventing cardiovascular events (6-9). Recent studies indicate that the function of circulating EPCs is impaired in obese individuals. However, the underlying mechanism remains unclear.

Adipose tissue can secrete many different adipokines. Studies indicate that abdominal obesity can change the levels of many adipokines (10-15). Visfatin is an adiponectin discovered in 2005. The effect of visfatin on the vascular inflammation in obesity and type 2 diabetes draws more and more attention. Visfatin possesses many biological functions. The function of visfatin is intimately correlated with glucose and lipid metabolism and can be considered a new proinflammatory factor which modulates the inflammatory processes of atherosclerosis (16-21). Research shows that there is an increased visfatin level in diabetic and obese patients $(22,23)$, which is related to vascular dysfunction (24).

Transcriptional factor nuclear factor $-\kappa \mathrm{B}(\mathrm{NF}-\kappa \mathrm{B})$ is a key inflammatory mediator, which can modulate the expression of a series of factors in the inflammatory processes. It is found that visfatin can upregulate the expression of $N F-\kappa B$ in human endothelium in umbilical veins, and lead to endothelial inflammation $(17,25)$. Based on these findings, we hypothesized that visfatin is an upstream influential factor leading to the decrease of EPCs in obese individuals by upregulating $\mathrm{NF}-\kappa \mathrm{B}$ in EPCs. Upregulated NF- $\mathrm{NB}$ induce inflammation and apoptosis of EPCs and results in decreased quantities of EPCs. At present, the relation of visfatin to EPCs is less investigated.

In the current study, we measured the quantity of EPCs, serum visfatin and expression of visfatin in visceral adipose tissue in high-fat-fed obese rats. The correlations of the above indices were analyzed. To observe the effect of visfatin on EPCs and to study the possible underlying mechanism, cultured primary EPCs were incubated with different concentrations of visfatin. The migration and adhesion ability and the protein expression of $\mathrm{NF}-\kappa \mathrm{B}$ in nuclei of EPCs were detected. We hope the present study can provide a potential new target for intervening with and preventing the development of vascular diseases in obese individuals.

\section{Materials and methods}

Animals. Male Wistar rats, 200-250 g of weight, were obtained from Hebei Medical University Animal Laboratory. Rats were randomly divided into two groups: normal control group $(\mathrm{NC}, \mathrm{n}=11)$ and high-fat-fed group $(\mathrm{HF}, \mathrm{n}=11)$. The animals were kept in a temperature-controlled room $\left(22 \pm 1^{\circ} \mathrm{C}\right)$ on a 12-h light/dark cycle with free access to food and water. The $\mathrm{NC}$ group animals were fed a standard lab diet $(65.5 \%$ calories from carbohydrate, $10.3 \%$ calories from fat, and $22.4 \%$ calories from protein; $384 \mathrm{kcal} / 100 \mathrm{~g}$ ). The $\mathrm{HF}$ group rats were fed a high-fat diet (20\% calories from carbohydrate, $60 \%$ calories from fat, and $20 \%$ calories from protein; $502 \mathrm{kcal} / 100 \mathrm{~g}$; Research Diets, Inc., USA). After a 16-week feeding, the Lee's index and body weight were measured. Lee's index = body weight $(\mathrm{g})^{1 / 3}$ x 1,000/body length $(\mathrm{cm})$. Animal studies and relative protocols were approved by the Animal Care and Use Committee at the Hebei Medical University.

Measurement of serum insulin and visfatin. Serum insulin and visfatin were detected by ELISA (sensitivity, $0.01 \mathrm{ng} / \mathrm{ml}$ and $1 \mathrm{ng} / \mathrm{ml}$, respectively) with an ALISEI microplate reader (Seac Srl, Italy).

Immunoblotting. Adipose tissue samples were homogenized in ice-cold lysis buffer (50 mM Tris $\mathrm{pH} 7.5,150 \mathrm{mM} \mathrm{NaCl}$, $1 \%$ Triton $\mathrm{X}-100,10 \mathrm{mM} \mathrm{NaP}, 100 \mathrm{mM} \mathrm{NaF}, 2 \mathrm{mM} \mathrm{Na}$ orthovanadate, $1 \mathrm{mM}$ EDTA, $1 \mathrm{mM}$ EGTA, $10 \%$ glycerol), supplemented with protease inhibitor cocktail tablets (Roche) and DL-dithiothreitol and solubilized for $30 \mathrm{~min}$ at $4^{\circ} \mathrm{C}$. Protein samples were then denatured in SDS sample buffer (125 mmol/1 Tris-HCl, pH 6.8, 50\% glycerol, 2\% SDS, 5\% $\beta$-mercaptoethanol, and $0.01 \%$ bromophenol blue). Equal amounts of tissue lysates (60 $\mu \mathrm{g}$ protein) were resolved by SDS-PAGE and immunoblotted with appropriate antibodies against visfatin (Biovision). Immunolabeled bands were quantitated by densitometry. To determine the protein contents of $\mathrm{NF}-\kappa \mathrm{B}$ in nuclei in EPCs, nuclear protein was extracted from cultured EPCs using a nuclear protein extraction kit (Applygen Technologies). Tissue lysates (60 $\mu \mathrm{g}$ protein) were resolved by SDS-PAGE and immunoblotted with appropriate antibodies against NF- $\kappa$ B (Santa Cruz Biotechnology, Inc.). Immunolabeled bands were quantitated by densitometry. $\beta$-tubulin (Abcam) was used as an internal standard.

Culture of EPCs. Hollow bones of rat legs were prepared by standard surgical procedures, and whole bone marrow was harvested by flushing marrow with $500 \mu$ l PBS using a syringe with a 20-gauge needle. Briefly, rat bone marrow mononuclear cells (MNCs) were isolated from flushing liquid by Ficoll density centrifugation. Cells were centrifuged for $30 \mathrm{~min}$ at room temperature $(1,000 \mathrm{rpm})$ for $10 \mathrm{~min}$. MNCs were isolated and washed with PBS. MNCs were resuspended in EGM-2MV medium (Lonza). Six-well or 24-well tissue culture plates precoated with fibronectin (Solarbio, China) were seeded at a density of $2 \times 10^{6} / \mathrm{ml}$ and cultured in a humidified incubator. After $48 \mathrm{~h}$ of culture, adherent cells were washed with EGM-2MV, and EGM-2MV medium was added to each well. The medium was changed daily for 7 days and then every other day until the first passage. Cells were observed daily under inverted microscopy.

Determination of EPCs numbers and cellular characterization. Immunocytochemistry was performed in cultured cells to detect the expression of CD34 and kinase insert domain receptor (KDR). CD34 and KDR also termed Flk-1 are surface markers of EPCs. Briefly, EPCs were fixed in $4 \%$ paraformaldehyde in PBS for 20 min, washed 3 times with PBS, and respectively stained with various EPCs specific markers: rabbit anti-rat CD34, mouse anti-rat KDR (Boster, China). The cells were incubated with secondary antibodies (either anti-mouse or anti-rabbit) and then in third antibody. Cells were colored with DAB and stained with hematoxylin.

Moreover, EPCs were characterized by cellular uptake of DiI-labeled acetylated LDL (DiI-acLDL; Molecular Probes, Eugene, OR, USA) and binding of fluorescein isothiocy- 
Table I. Basic characteristic data in rats of the two groups (mean $\pm \mathrm{SD}$ ).

\begin{tabular}{lcccccccc}
\hline Index & $\begin{array}{c}\text { Lee's } \\
\text { index }\end{array}$ & $\begin{array}{c}\text { BW } \\
(\mathrm{g})\end{array}$ & $\begin{array}{c}\text { VAT } \\
(\mathrm{g})\end{array}$ & $\begin{array}{c}\text { FBG } \\
(\mathrm{mmol} / \mathrm{l})\end{array}$ & $\begin{array}{c}\text { FINS } \\
(\mathrm{ng} / \mathrm{l})\end{array}$ & HOMA-IR & $\begin{array}{c}\text { TG } \\
(\mathrm{mmol} / \mathrm{l})\end{array}$ & $\begin{array}{c}\text { TC } \\
(\mathrm{mmol} / \mathrm{l})\end{array}$ \\
\hline $\mathrm{NC}$ & $296.66 \pm 9.01$ & $405 \pm 18$ & $15.45 \pm 1.13$ & $4.06 \pm 0.40$ & $2.03 \pm 0.56$ & $0.37 \pm 0.11$ & $0.61 \pm 0.12$ & $0.91 \pm 0.13$ \\
$\mathrm{HF}$ & $310.57 \pm 9.52^{\mathrm{a}}$ & $453 \pm 36^{\mathrm{b}}$ & $19.45 \pm 3.05^{\mathrm{b}}$ & $5.77 \pm 0.84^{\mathrm{b}}$ & $3.17 \pm 0.87^{\mathrm{b}}$ & $0.83 \pm 0.29^{\mathrm{b}}$ & $0.97 \pm 0.24^{\mathrm{b}}$ & $1.29 \pm 0.20^{\mathrm{b}}$ \\
\hline
\end{tabular}

Compared with the NC group: ${ }^{a} \mathrm{P}<0.05,{ }^{\mathrm{b}} \mathrm{P}<0.01$. NC, normal control; HF, high-fat-fed group; $\mathrm{BW}$, body weight; VAT, visceral adipose tissue; FBG, fasting blood glucose; FINS, fasting insulin in serum; HOMA-IR, homeostasis model assessment-insulin resistance; TG, triglyceride; TC, total cholesterol.

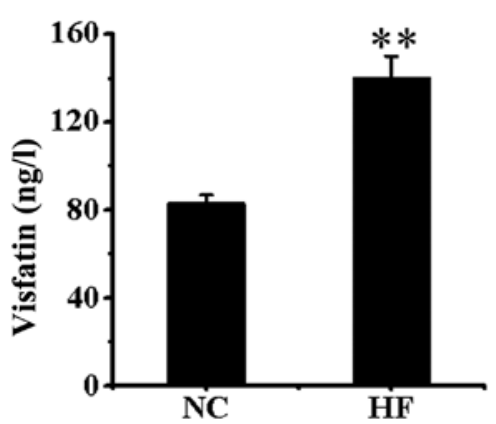

Figure 1. The fasting serum visfatin levels at the end of the 16 th week in the normal control (NC) and high-fat-fed (HF) groups. ${ }^{* *} \mathrm{P}<0.01$ vs. NC.

anate-conjugated lectin from Ulex europaeus agglutinin (FITC-Lectin-UEA-1; Sigma). Briefly, after 10-day culture, Dil-acLDL $(2.5 \mu \mathrm{g} / \mathrm{ml})$ were added on cells for $4 \mathrm{~h}$ and washed for 3 times. After fixing in 2\% paraformaldehyde for $20 \mathrm{~min}$, FITC-Lectin-UEA-1 $(10 \mu \mathrm{g} / \mathrm{ml})$ were added and cultured for $1 \mathrm{~h}$. The cells were then observed under laser scanning confocal microscopy. Orange double-stained cells positive for both DiI-acLDL and FITC-Lectin-UEA-1 were identified as EPCs. EPCs were counted under laser scanning confocal microscopy.

Treatment of EPCs by visfatin incubation. Bone marrow MNCs from male Wistar rats fed a standard diet were isolated and cultured as described. EPCs were determined from MNCs and treated with visfatin at different concentrations $(0,50,100$, $150,200 \mathrm{ng} / \mathrm{ml}$ ) for $48 \mathrm{~h}$.

Evaluation of the migration capacity of EPCs. Single cell suspension were planted in 24-well plate as a density of $5 \times 10^{4} / \mathrm{ml}$. After 24-h culture, cells were digested with $0.25 \%$ trypsin solution and counted. Culture medium were added into the lower chamber of a modified Boyden chamber; $2 \times 10^{4} / \mathrm{ml}$ of EPCs were suspended in $150 \mu \mathrm{l}$ of medium and added into the upper chamber. After $24 \mathrm{~h}$ of culture, the unmoved cells were scratched from the filtration membrane. The migrated cells were fixed with formalin and stained with hematoxylin. Ten fields were randomly chosen to count the migrated cells under inverted microscopy (x400).

Evaluation of adhesion capacity of EPCs. Single cell suspensions were plated in 24-well plates at a density of $5 \times 10^{4} / \mathrm{ml}$. After 24-h culture, cells were digested with $0.25 \%$ trypsin solution. Equal numbers of cells were plated into 96 -well plate and incubated for $30 \mathrm{~min}$ at $37^{\circ} \mathrm{C}$. Unattached cells were

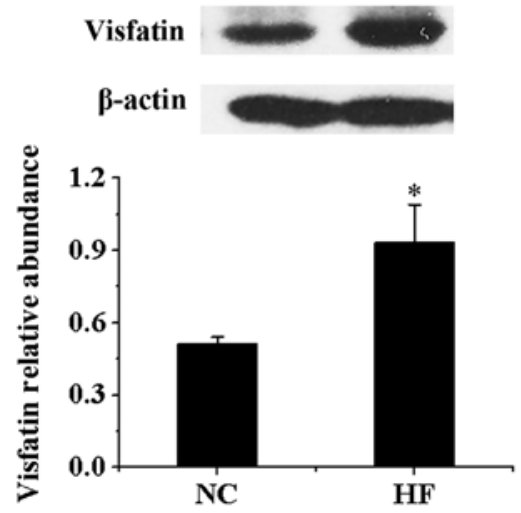

Figure 2. Protein contents of visfatin in viceral adipose tissue in the normal control (NC) and high-fat-fed (HF) groups of rats. ${ }^{*} \mathrm{P}<0.05$ vs. NC.

washed out. Ten fields were randomly chosen to count the attached cells under inverted microscopy (x400).

Statistical analyses. Data are presented as means \pm SE. The data were tested by homogeneity test for variance. The t-test was used for comparison of normally distributed data with homogenous variance. The rank sum test was used for comparison of normally distributed data with heterogenous variance. One-way analysis of variance was used for comparison of normally distributed data with homogeneous variance relevant groups. Linear regression was used to detect a correlation. Differences at $\mathrm{P}<0.05$ were considered to be statistically significant.

\section{Results}

Comparison of baseline characteristics between $\mathrm{NC}$ and $\mathrm{HF}$ groups. Lee's index, body weight (BW), visceral adipose tissue (VAT), fasting blood glucose (FBG), fasting insulin in serum (FINS), homeostasis model assessment-insulin resistance (HOMA-IR), plasma triglyceride (TG), plasma total cholesterol (TC) were all significantly higher in the HF group than in the NC group (Table I).

Visfatin level in serum. Serum visfatin was significantly higher in the HF group than in the $\mathrm{NC}$ group $(\mathrm{P}<0.01)$ (Fig. 1).

Protein expression of visfatin in VAT. Compared with NC group, the protein contents of visfatin in VAT in HF group were significantly higher compared with the NC group $(\mathrm{P}<0.05)$ (Fig. 2). 
A

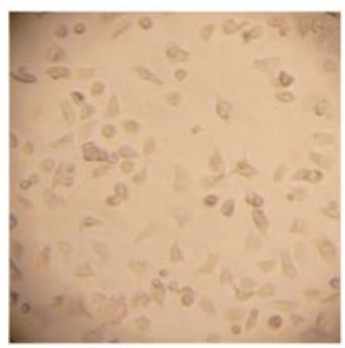

B

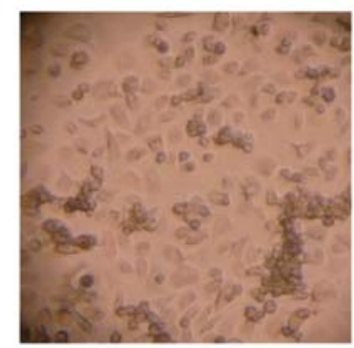

$\mathrm{C}$

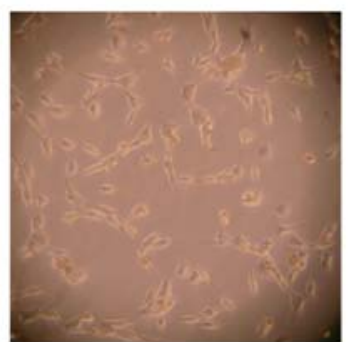

$\mathrm{D}$

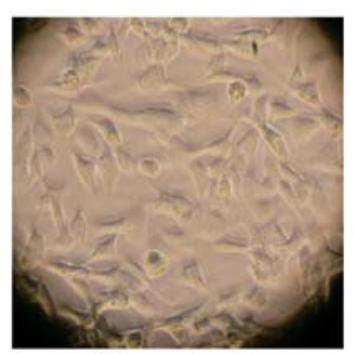

$\mathrm{E}$

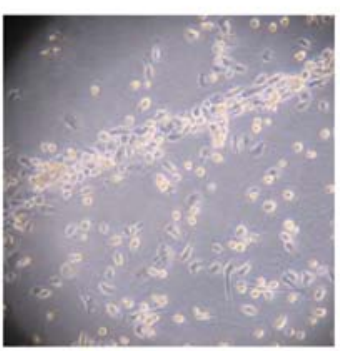

Figure 3. Culture of bone marrow mononuclear cells (MNCs). Bone marrow mononuclear cells (MNCs) were isolated and cultured from legs of rats of each group. Morphology of MNCs under inverted microscopy. Isolated marrow MNCs after culture for (A) 48 h (x200), (B) 4 days (x200), (C) 7 days (x200), (D) 7 days (x400) and (E) 10 days (x200).

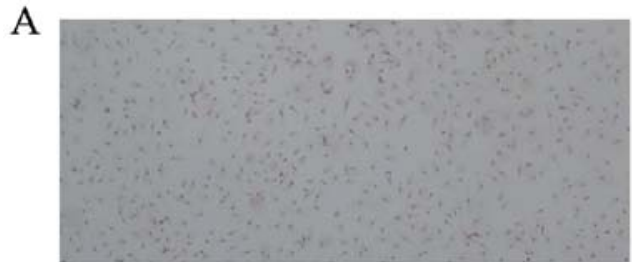

B

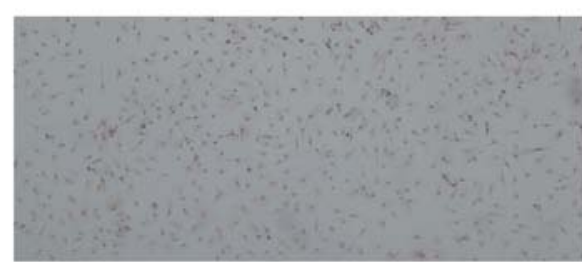

$\mathrm{C}$

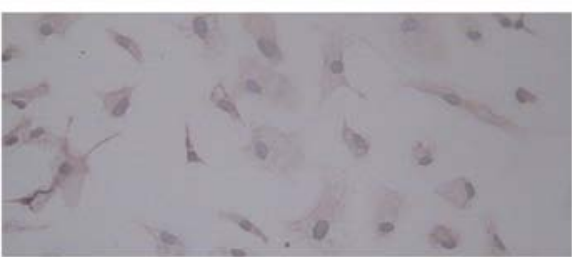

$\mathrm{E}$

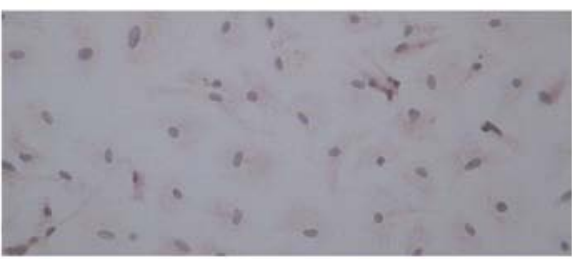

$\mathrm{D}$

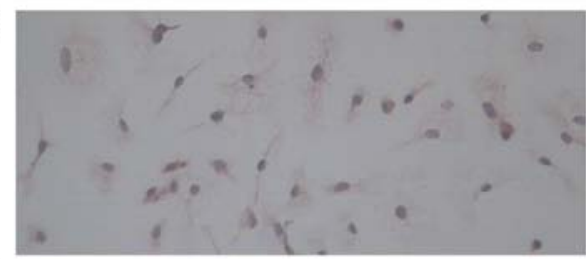

F

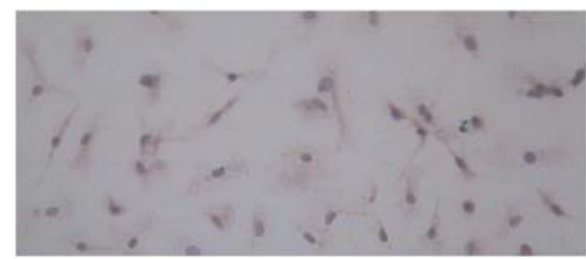

Figure 4. EPCs phenotyping. Immunocytochemistry was performed in cultured cells to detect the expression of CD34 and the kinase insert domain receptor (KDR). (A) CD34 expression in EPCs (x100); (B) KDR expression in EPCs (x100); (C) CD34 expression in HF EPCs (x400); (D) KDR expression in HF EPCs (x400); (E) CD34 expression in NC EPCs (x400); (F) KDR expression in NC EPCs (x400).
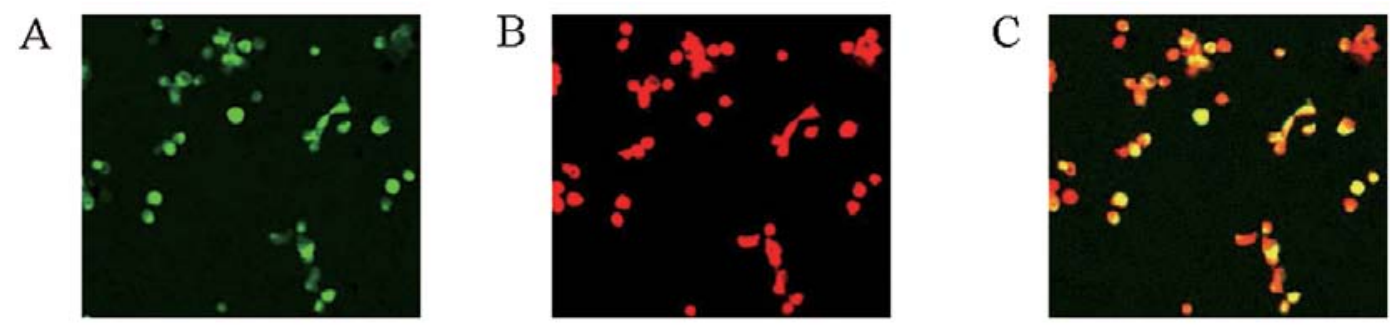

Figure 5. Determination of EPCs. EPCs were determined by cellular uptake of acetylated LDL (Dil-acLDL) and binding of fluorescein isothiocyanateconjugated lectin. Morphology of EPCs was observed under laser scanning confocal microscopy. (A) FITC-Lectin-UEA-1 combined by EPCs (green); (B) DIL-Ac-LDL uptaken by EPCs (red); (C) EPCs stained with FITC-Lectin-UEA-land DIL-Ac-LDL (orange). 

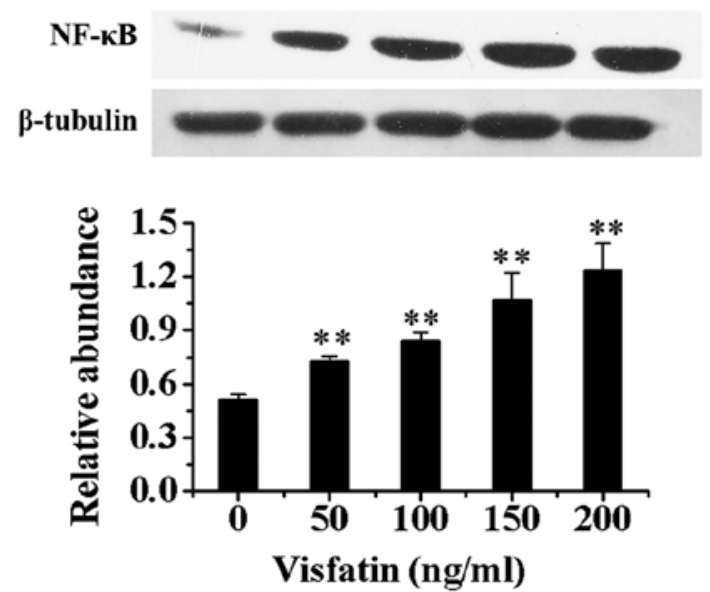

Figure 6. Protein contents of NF-кB after EPCs were incubated with visfatin for $48 \mathrm{~h}$ at different concentrations $(0,50,100,150$ and $200 \mathrm{ng} / \mathrm{ml})$. The protein expression of NF- $\mathrm{KB}$ in EPCs after treatment with different concentrations of visfatin was increased in a dose-dependent manner. ${ }^{* * *} \mathrm{P}<0.01$ vs. NC).

Table II. Number of EPCs in the normal control (NC) and high-fat-fed (HF) groups (mean $\pm \mathrm{SD}$ ).

\begin{tabular}{ccc}
\hline & $\mathrm{NC}$ & $\mathrm{HF}$ \\
\hline EPCs & $72.59 \pm 4.22$ & $63.23 \pm 5.33^{\mathrm{a}}$ \\
\hline
\end{tabular}

${ }^{a} \mathrm{P}<0.01$, compared with the $\mathrm{NC}$ group.

Culture of EPCs. Newly isolated bone marrow mononuclear cells were round, transparent and suspended in medium. After $48 \mathrm{~h}$ of plating, part of the cells attached. The adherent cells gradually enlarged and stretched. After 4-7 days of plating adherent cells grew as colonies. Cells were round, triangle, oval or irregular. After 10 days, cell were linearly arranged (Fig. 3).

Determination of EPCs numbers and cellular characterization. EPCs were analyzed by immunohistochemical staining under a microscope. CD34 and KDR are surface markers of EPCs (Fig. 4).

After a 10-day culture, by uptake of DIL-Ac-LDL and binding of FITC-Lectin-UEA-1, EPCs which were doublestained cells as yellow were observed and counted under laser scanning confocal microscopy. The numbers of EPCs were significantly lower in the HF group compared with those in the NC group $(\mathrm{P}<0.01)$ (Table II) (Fig. 5).

Correlation analysis of different index. The Pearson correlation analysis indicated that the numbers of EPCs were negatively correlated with serum visfatin $(\mathrm{r}=-0.886, \mathrm{P}<0.01)$, CRP ( $\mathrm{r}=-0.849, \mathrm{P}<0.01)$, FBG ( $\mathrm{r}=-0.753, \mathrm{P}<0.01)$, HOMA-IR $(\mathrm{r}=-0.775, \mathrm{P}<0.01), \mathrm{TC}(\mathrm{r}=-0.744, \mathrm{P}<0.01)$, TG $(\mathrm{r}=-0.821$, $\mathrm{P}<0.01)$, VAT $(\mathrm{r}=-0.631, \mathrm{P}<0.01)$ and $\mathrm{BW}(\mathrm{r}=-0.656, \mathrm{P}<0.01)$.

Effect of visfatin treatment on EPCs. Compared with EPCs without incubation of visfatin, the protein expression of NF- $\mathrm{kB}$ in nuclei in EPCs after treatment with different concentrations
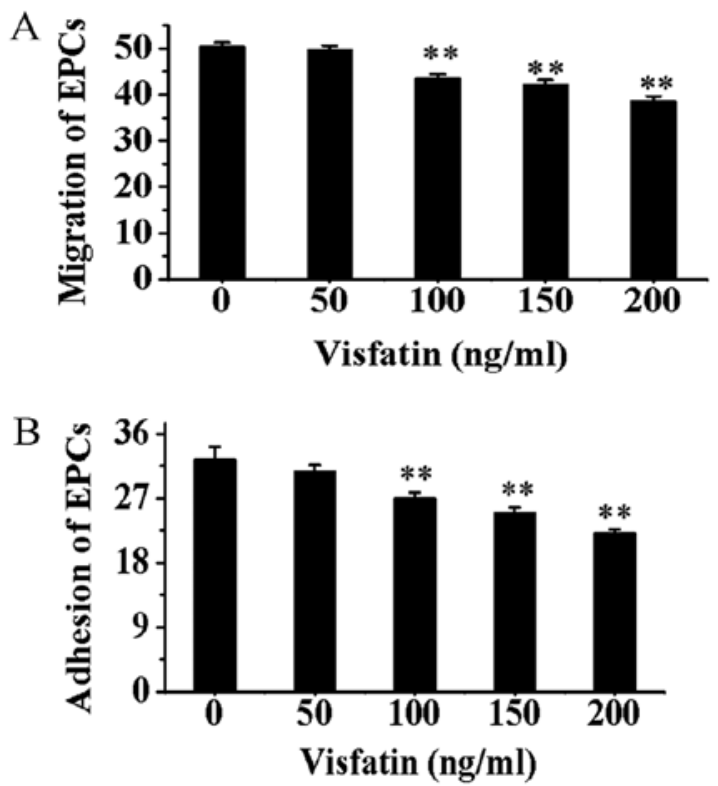

Figure 7. Migration and adhesive capacity of EPCs after culture in visfatin for $48 \mathrm{~h}$ in different concentrations $(0,50,100,150,200 \mathrm{ng} / \mathrm{ml})$. (A) Compared with EPCs without incubation of NF- $\kappa \mathrm{B}$, the migration capacities of EPCs treated with NF- $\kappa \mathrm{B}$ gradually decreased in a dose-dependent manner $(\mathrm{P}<0.01)$. (B) Compared with EPCs without incubation of NF- $\mathrm{B}$, the adhesion capacities of EPCs treated with $\mathrm{NF}-\kappa \mathrm{B}$ were gradually decreased in a dose-dependent manner ( ${ }^{* *} \mathrm{P}<0.01$ vs. $\left.\mathrm{NC}\right)$.

of visfatin increased in a dose-dependent manner $(\mathrm{P}<0.01)$ (Fig. 6).

Compared with EPCs without incubation of visfatin, the migration and adhesion capacities of EPCs treated with visfatin were gradually decreased in a dose-depent manner $(\mathrm{P}<0.01)$ (Fig. 7).

\section{Discussion}

Obesity has become increasingly prevalent and is an important risk factor of cardiovascular disease (26-29). Studies indicate that obesity, similarly to other risk factors including diabetes mellitus, hypertension and smoking, can impair the function of the vascular endothelium (30-33) and lead to arteriosclerosis and other cardiovascular diseases (6-9). Endothelial progenitor cells (EPCs) play an important role in maintaining the complement of endothelial structure and normal function of the vascular endothelium. EPCs originate from the bone marrow. EPCs released into the blood circulation after stimulation can differentiate into mature endothelial cells and especially settle in ischemic locations and participate in the re-endothelialization of injured blood vessels. According to previous studies, the alterations in EPCs exist in overweight and obese individuals. Several recent studies show that the numbers of EPCs decreased in overweight and obese populations with an impaired proliferation capacity (34-39). Heida et al (34) found that the numbers of EPCs in the blood circulation decreased in obese individuals and obese mice; meanwhile, the migration and adhesion capacity of EPCs were impaired. MacEneaney et al (35) also found an decrease in EPCs quantity in overweight and obese individuals with an weakened proliferation capacity. However, the underlying 
mechanism by which the quantity and function of EPCs are impaired remain unclear.

Visfatin is an adipokine which is secreted by adipose tissue. The effects of visfatin include promoting the differentiation of adipose cells and the synthesis and storage of adipose tissue, promoting inflammation of vascular endothelial cells and leading to the development of arteriosclerosis (16,40-43). By far, the possible relationship of visfatin to EPCs is less investigated. We hypothesized that visfatin might be involved in the impairment of EPCs function in the situation of obesity. In the present study, we fed the rats with a high-fat diet for 16 weeks and induced obesity in rats along with the development of whole body insulin resistance (as shown by increased FBG, FINS and HOMA-IR). EPCs were significantly decreased in rats in HF group, which is consistent with previous studies. Meanwhile, serum visfatin and the protein contents of visfatin were significantly increased by high fat feeding. Correlation analysis indicated that the quantity of EPCs are negatively correlated with visfatin levels, indicating a possible relationship of visfatin to EPCs and that visfatin is possibly an influential factor of the quantity of EPCs.

A possible underlying mechanism of the influence of visfatin on EPCs quantity might be the inflammatory effect of visfatin. Previous studies found that visfatin induces the upregulation of inflammatory factors and adhesion molecules in human umbilical vein endothelial cells (HUVECs) through the NF- $\kappa$ B pathway $(17,20,21,25)$. Lee et al $(17)$ found that the activity of NF- $\kappa \mathrm{B}$ was increased in HUVECs after incubation with visfatin, with the upregulation of IL-6, IL-8, ICAM-1, VCAM-1 and E-selectin genes. The activity of NF- $\kappa \mathrm{B}$ increased in both HUVECs and epithelial tumor cells when incubated with visfatin for $24 \mathrm{~h}$; the activity increased with the treatment of visfatin in a dose-dependent manner (25). Furthermore, visfatin can increase the expression of NF- $\kappa \mathrm{B}$, tumor necrosis factor- $\alpha$ (TNF- $\alpha$ ), matrix metalloproteinase- 9 (MMP-9), interleukin-8 (IL-8), IL-6 in monocytes by activating insulin receptor (IR)-Ras-MAPK signaling pathway and the insulin-independent p38 pathway (16). Based on these findings, we presume that visfatin might influence the function of EPCs through the NF- $\kappa \mathrm{B}$ pathway.

In our study, we incubated the EPCs with different concentrations of visfatin to observe the effect of visfatin on the expression of $\mathrm{NF}-\kappa \mathrm{B}$ in nuclei of EPCs. The concentration of visfatin was based on serum visfatin levels measured in the animal study. The results show that the expression of $\mathrm{NF}-\kappa \mathrm{B}$ in nuclear EPCs were significantly increased by visfatin treatment in a dose-dependent manner, which is consistent with the previous study that visfatin possesses inflammatory effects. The effect of visfatin on NF- $\mathrm{BB}$ in EPCs support our hypothesis that visfatin may have an effect on EPCs through the NF- $\mathrm{NB}$ pathway. Meanwhile, the capacity of EPCs to migrate and adhere was impaired by visfatin treatment. The possible mechanism is that inflammation induced by visfatin causes the upregulation of a series of inflammatory factors including $\mathrm{NF}-\kappa \mathrm{B}$ and $\mathrm{TNF}-\alpha$, leading to the aging and apoptosis of EPCs and resulting in decreased quantities and impaired functions of EPCs (44-46). Further investigation is warranted.

In summary, serum visfatin and protein contents of visfatin in VAT increased in obese rats fed a high-fat diet, accompanied with decreased quantities of bone-marrow originating EPCs. Visfatin may be involved in the development of decreased EPC numbers and impaired functions through the NF- $\kappa \mathrm{B}$ pathway. The present study provides a new target for prevention of the development of cardiovascular disease in obese populations.

\section{Acknowledgements}

We thank Mr. Chao Wang for continuous advice, support and technical assistance.

\section{References}

1. Laufs U, Urhausen A, Werner N, et al: Running exercise of different duration and intensity: effect on endothelial progenitor cells in healthy subjects. Eur J Cardiovasc Prev Rehabil 12: 407-414, 2005

2. Hill JM, Zalos G, Halcox JP, et al: Circulating endothelial progenitor cells, vascular function, and cardiovascular risk. N Engl J Med 348: 593-600, 2003.

3. Fadini GP, Miorin M, Facco M, et al: Circulating endothelial progenitor cells are reduced in peripheral vascular complications of type 2 diabetes mellitus. J Am Coll Cardiol 45: 1449-1457, 2005.

4. Fadini GP, Sartore S, Albiero M, et al: Number and function of endothelial progenitor cells as a marker of severity for diabetic vasculopathy. Arterioscler Thromb Vasc Biol 26: 2140-2146, 2006.

5. Fadini GP, Sartore S, Agostini C and Avogaro A: Significance of endothelial progenitor cells in subjects with diabetes. Diabetes Care 30: 1305-1313, 2007.

6. Meyers MR and Gokce N: Endothelial dyfuntion in obesity: etiological role in atherosclerosis. Curr Opin Endocrinol Diabetes Obes 14: 365-369, 2007.

7. Reriani MK, Lerman LO and Lerman A: Endothelial function as a functional expression of cardiovascular risk factors. Biomark Med 4: 351-360, 2010.

8. Chung IM, Kim YM, Yoo MH, et al: Immobilization stress induces endothelial dysfunction by oxidative stress via the activation of the angiotensin II/its type I receptor pathway. Atherosclerosis 213: 109-114, 2010.

9. Sitia S, Tomasoni L, Atzeni F, et al: From endothelial dysfunction to atherosclerosis. Autoimmun Rev 9: 830-834, 2010.

10. Kouidhi S, Jarboui S, Marrakchi R, et al: Adiponectin expression and metabolic markers in obesity and type 2 diabetes. J Endocrinol Invest 34: e16-e23, 2011.

11. Mangge H, Almer G, Truschnig-Wilders M, et al: Inflammation, adiponectin, obesity and cardiovascular risk. Curr Med Chem 17: 4511-4520, 2010.

12. Yun JE, Kimm H, Jo J and Jee SH: Serum leptin is associated with metabolic syndrome in obese and nonobese Korean populations. Metabolism 59: 424-429, 2010.

13. Hecker PA, O'Shea KM, Galvao TF, et al: Role of adiponectin in the development of high fat diet-induced metabolic abnormalities in mice. Horm Metab Res 43: 100-105, 2011.

14. Chang J, Li Y, Huang Y, et al: Adiponectin prevents diabetic premature senescence of endothelial progenitor cells and promotes endothelial repair by suppressing the p38 MAP kinase/ p16INK4A signaling pathway. Diabetes 59: 2949-2959, 2010.

15. Lavoie V, Kernaleguen AE, Charron G, et al: Functional effects of adiponectin on endothelial progenitor cells. Obesity 19: 722-728, 2011.

16. Moschen AR, Kaser A, Enrich B, et al: Visfatin, an adipocytokine with proinflammatory and immunomodulating properties. J Immunol 178: 1748-1758, 2007.

17. Lee WJ, Wu CS, Lin H, et al: Visfatin-induced expression of inflammatory mediators in human endothelial cells through the NF-kappaB pathway. Int J Obes 33: 465-472, 2009.

18. Huang F, Xiong XF, You S, et al: Visfatin upregulates MMP-2 and MMP-9 expressions in human monocytes through activating NF-kappaB. Zhonghua Xin Xue Guan Bing Za Zhi 38: 455-459, 2010 (In Chinese).

19. Kim SR, Bae YH, Bae SK, et al: Visfatin enhances ICAM-1 and VCAM-1 expression through ROS-dependent NF-kappaB activation in endothelial cells. Biochim Biophys Acta 1783: 886-895, 2008. 
20. Chang YC, Chang TJ, Lee WJ and Chuang LM: The relationship of visfatin/pre-B-cell colony-enhancing factor/nicotinamide phosphoribosyltransferase in adipose tissue with inflammation, insulin resistance, and plasma lipids. Metabolism 59: 93-99, 2010.

21. Kang YS, Song HK, Lee MH, et al: Plasma concentration of visfatin is a new surrogate marker of systemic inflammation in type 2 diabetic patients. Diabetes Res Clin Pract 89: 141-149, 2010.

22. Dogru T, Sonmez A, Tasci I, et al: Plasma visfatin levels in patients with newly diagnosed and untreated type 2 diabetes mellitus and impaired glucose tolerance. Diabetes Res Clin Pract 76: 24-29, 2007

23. Fukuhara A, Matsuda M, Nishizawa M, et al: Visfatin: a protein secreted by visceral fat that mimics the effects of insulin. Science 307: 426-430, 2005

24. Takebayashi K, Suetsugu M, Wakabyashi S, et al: Association between plasma visfatin and vascular endothelial function in patients with type 2 diabetes mellitus. Metabolism 56: 451-458, 2007.

25. Adya R, Tan BK, Chen J and Randeva HS: Nuclear factor-kappaB induction by visfatin in human vascular endothelial cells: role in MMP-2/9 production and activation. Diabetes Care 31: 758-760, 2008.

26. Doupis J, Rahangdale S, Gnardellis C, et al: Effects of diabetes and obesity on vascular reactivity, inflammatory cytokines, and growth factors. Obesity 19: 729-735, 2011.

27. Yan LL, Daviglus ML, Liu K, et al: Midlife body mass index and hospitalization and mortality in older age. JAMA 295: 190-198, 2006.

28. Akil L and Ahmad HA: Relationships between obesity and cardiovascular diseases in four southern states and Colorado. J Health Care Poor Underserved 22 (Suppl 4): 61-72, 2011.

29. DeClercq V, Taylor C and Zahradka P: Adipose tissue: the link between obesity and cardiovascular disease. Cardiovasc Hemato Disord Drug Targets 8: 228-237, 2008.

30. Barton M: Obesity and aging: determinants of endothelial cell dysfunction and atherosclerosis. Pflugers Arch 460: 825-837, 2010.

31. Kobayasi R, Akamine EH, Davel AP, et al: Oxidative stress and inflammatory mediators contribute to endothelial dysfunction in high-fat diet-induced obesity in mice. J Hypertens 28: 2111-2119, 2010.

32. Ketonen J, Shi J, Martonen E and Mervaala E: Periadventitial adipose tissue promotes endothelial dysfunction via oxidative stress in diet-induced obese C57B1/6 mice. Circ J 74: 1479-1487, 2010.

33. Short KR, Blackett PR, Gardner AW and Copeland KC: Vascular health in children and adolescents: effects of obesity and diabetes. Vasc Health Risk Manag 5: 973-990, 2009.
34. Heida NM, Müller JP, Cheng IF, et al: Effects of obesity and weight loss on the functional properties of early outgrowth endothelial progenitor cells. J Am Coll Cardiol 55: 357-367, 2010.

35. MacEneaney OJ, Kushner EJ, Van Guilder GP, et al: Endothelia progenitor cell number and colony-forming capacity in overweight and obese adults. Int J Obes (Lond) 33: 219-225, 2009.

36. MacEneaney OJ, Kushner EJ, Westby CM, et al: Endothelial progenitor cell function, apoptosis, and telomere length in overweight/obese humans. Obesity 18: 1677-1682, 2010.

37. Tobler K, Freudenthaler A, Baumgartner-Parzer SM, et al Reduction of both number and proliferative activity of human endothelial progenitor cells in obesity. Int J Obes (Lond) 34: 687-700, 2010

38. Westerweel PE, Visseren FL, Hajer GR, et al: Endothelial progenitor cell levels in obese men with the metabolic syndrome and the effect of simvastatin monotherapy vs. simvastatin/ ezetimibe combination therapy. Eur Heart J 29: 2808-2817, 2008.

39. Esposito K, Ciotola M, Maiorino MI, et al: Circulating CD34 $\mathrm{KDR}^{+}$endothelial progenitor cells correlate with erectile function and endothelial function in overweight men. J Sex Med 6: 107-114, 2009.

40. Malyszko J, Malyszko JS and Mysliwiec M: Visfatin and endothelial function in dialyzed patients. Nephrology (Carlton) 15: 190-196, 2010.

41. Schutte AE, Huisman HW, Schutte R, et al: Adipokines and cardiometabolic function: How are they interlinked? Regul Pept 164: 133-138, 2010.

42. Moschen AR, Gerner RR and Tilg H: Pre-B cell colony enhancing factor/NAMPT/visfatin in inflammation and obesityrelated disorders. Curr Pharm Des 16: 1913-1920, 2010.

43. Moschen AR, Geiger S, Gerner R and Tilg H: Pre-B cell colony enhancing factor/NAMPT/visfatin and its role in inflammationrelated bone disease. Mutat Res 690: 95-101, 2010.

44. Verma S, Kuliszewski MA, Li SH, et al: C-reactive protein attenuates endothelial progenitor cell survival, differentiation, and function: further evidence of a mechanistic link between C-reactive protein and cardiovascular disease. Circulation 109: 2058-2067, 2004.

45. Suh W, Kim KL, Choi JH, et al: C-reactive protein impairs angiogenic functions and decreases the secretion of arteriogenic chemo-cytokines in human endothelial progenitor cells. Biochem Biophys Res Commun 321: 65-71, 2004.

46. Nan JL, Li JJ and He JG: C-reactive protein decreases interleukin-8 production in human endothelial progenitor cells by inhibition of p38 MAPK pathway. Chin Med J (Engl) 122: 1922-1928, 2009. 